\title{
A FACIAL RECOGNITION USING OPEN COMPUTER VISION
}

\author{
Dr.C K Gomathy \\ Assistant Professor, \\ Department of CSE \\ SCSVMV Deemed to be University, TN, India
}

\author{
T.suneel \\ UG Student \\ Department of CSE \\ SCSVMV Deemed to be University, TN, India
}

\author{
Y.Jeeevan Kumar Reddy \\ UG Student \\ Department of CSE \\ SCSVMV Deemed to be University, TN, India
}

\begin{abstract}
The Face recognition and image or video recognition are popular research topics in biometric technology. Real-time face recognition is an exciting field and a rapidly evolving issue. Key component analysis (PCA) may be a statistical technique collectively called correlational analysis. The goal of PCA is to scale back the massive amount of knowledge storage to the dimensions of the functional space required to render the face recognition system. The wide one-dimensional pixel vector generated from the two-dimensional image of the face and therefore the basic elements of the spatial function are designed for face recognition using PCA. this is often the projection of your own space. Sufficient space is decided by the brand. specialise in the eigenvectors of the covariance matrix of the fingerprint image collection. $i$ 'm building a camera-based real-time face recognition system and installing an algorithm. Use OpenCV, Haar Cascade, Eigen face, Fisher Face, LBPH and Python for program development.
\end{abstract}

Keywords: Face recognition, face detection, Computer vision, and Recognition mechanisms

\section{INTRODUCTION}

The face is our primary consciousness of interest in social lifestyles gambling an crucial position in conveying identification and emotions. we will apprehend a number of faces acknowledged throughout our lifespan and perceive faces at a glance even after years of separation. This talent is pretty sturdy no matter of giant versions in visible stimulus thanks to converting condition, growing older and distractions consisting of beard, glasses or changes in hairstyle. Computational fashions of face reputation are exciting thanks to the very fact they're ready to make a contribution now not handiest to theoretical expertise however additionally to practical applications. Computers that encounter and apprehend faces are often administered to an enormous kind of responsibilities which include crook identification, safety system, image and movie processing, identification verification, tagging functions and human-computer interaction. Unfortunately, growing a computational version of face detection and reputation is pretty tough thanks to the very fact faces are complex, multidimensional and significant visible stimuli. Face detection is employed in many locations now each day particularly the online sites web website hosting photographs like picassa, photo bucket and Facebook. The routinely tagging function provides a fresh measurement to sharing pictures most of the parents that are withinside the image and additionally offers the concept to different people approximately who the person or woman is withinside the image. In our project, we have got studied and administered a quite easy however very powerful face detection set of rules which takes human pores and skin coloration under consideration. Our aim, which we accept as true with we have got reached, become to extend a way of face reputation this is often fast, sturdy, moderately easy and proper with a rather easy and smooth to know algorithms and techniques. The examples supplied on this thesis are real-time and brought from our personal surroundings.

\section{LITERATURE SURVEY}

In the present, advances of PC imaginative and prescient are efficiently creating, with their assistance; we will address a drag all of the greater adequately, certainly considered one of that's acknowledgment. due to dynamic development, designers get limitless libraries to require care of problems related to PC imaginative and prescient. Works middle across the hypothetical elements of constructing a continuing framework for face acknowledgment. This paper portrays the important techniques and advances for all levels of the event of the acknowledgment framework, seeing that withinside the topic of acknowledgment, a huge quantity of certainly 
considered one of type preparations had been created. This paper may be a usage of face identity and following in recordings and cameras making use of Open CV. It makes use of calculations like Adaboost, Haar direction. Face identity is that the maximum unmistakable region of studies withinside the imaginative and prescient of PC constructing. it's a PC improvement that's being utilized during a grouping of employments that acknowledges human faces in reducing side pictures. Face identity is one among the utmost mentioned in innovation. Face limit are often alluded to as extraction of facial highlights making use of design acknowledgment framework. Both MATLAB and Open CV could also be applied for execution. For the utmost element this paper makes use of three calculations named Haar Cascades, Cam Shift Algorithm, locating with the help of motion. Out of these Haar Cascade is that the fine calculation in mild of the very fact. Initially, it had been tedious, but after the modified variation it isnt that tedious. it's effective in execution and applied prevalently. Haar Cascades makes use of the photograph subtraction morphological method to know the face. during this the falls of exclusive pix of a comparative character is taken and recorded with inside the database. All of the pixels with inside the impact of white territory are subtracted from all the pixels with inside the impact of dim district. This process for subtraction is completed on all the photograph with inside the direction besides all the pix maximum probable wont supply us the fine results. This paper appears in the least of the calculation as an extended way as lifestyles worldview. It distinguishes Haar falls because the utmost gifted technique for face discovery. As we mentioned the exclusive calculations we observed that the calculations, for instance, Haar falls, camshaft calculation supply a advanced execution and a drastically greater checked yield than area thru motion but to the quantity time is taken into account camshaft calculation and identity with the help of motion calculation may be a advanced alternative. Subsequently, Haar falls works offers higher exactness in outward appearance.

\section{EXISTING SYSTEM}

In the present gadget the whole manner of facial popularity are executed by the utilization of internet cam. Facial reputation software program is based totally at the capacity to first understand faces, that's a technological feat in itself. If we examine the mirror, we'll see that your face has sure distinguishable land marks. These are the peaks and valleys that structure the special countenance. There are many advantages to face popularity structures alongside its convenience and social acceptability. All you would like is your image taken for it to figure. The system is simple to use and in many instances it's ready to be executed without a individual even knowing. Face detection is likewise one among the most cost effective biometric with inside the market and its fee got to be endured to go down. Face popularity structures can't inform the excellence among equal twins.

\section{PROPOSED SYSTEM}

Face recognition technology operate using the subsequent four stages. The bodily samples is captured or taken through the device at some point of enrolment and additionally in identity or verification process. the precise records is extracted from the pattern and a template is made. The template is then as compared with a fresh sample. The gadget involves a choice if the functions extracted from the new (i.e., suit or non-suit).For face popularity there are sorts of comparisons. the primary is verification and 2nd is identity. Verification is during which the device compares the given character with who that folks says they'll be and offers a sure or no decision. Identity is during which the device compares the given character to all or any the various people with inside the facts base and offers an inventory of matches. Given an photograph to become conscious of it as a face and/or extract face photograph from it. To retrieve comparable pix we need to take from the given statistics base of face pix.

\section{SYSYEM ARCHITECTURE}

Face reputation takes a picture from a video or a virtual digital digicam as enter and outputs the diagnosed image concern matter. Facial capabilities can also moreover include regions within the face, versions inside the face structure, face cuts and angles that are formatted and styled. Face extraction consists of grabbing of the skills from digital digicam

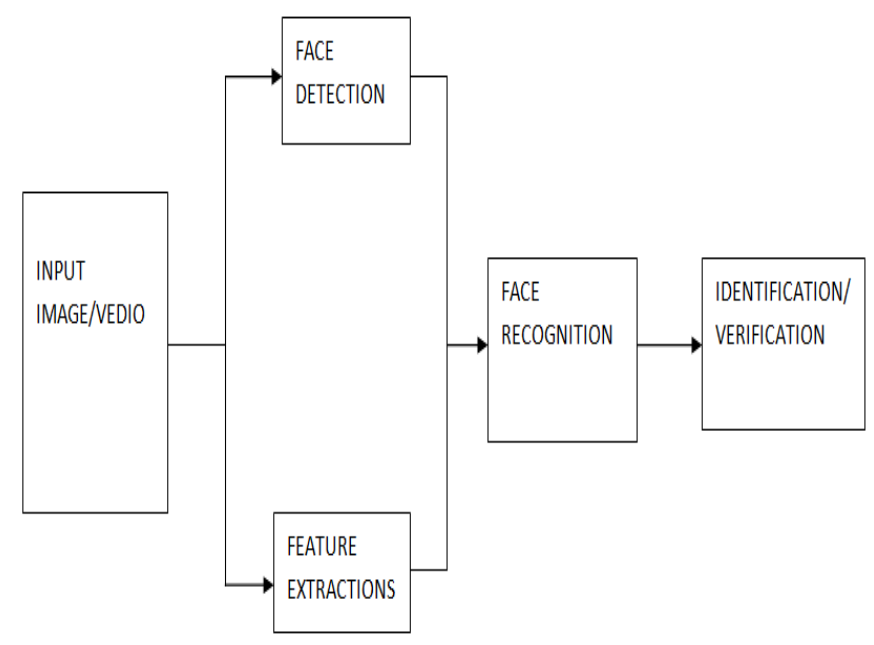

Fig 1: Face Detection Mechanism

Face detection consists of the removal of the heritage and focusing at the foreground removing a couple of various 


\section{International Journal of Engineering Applied Sciences and Technology, 2021 \\ Vol. 5, Issue 12, ISSN No. 2455-2143, Pages 322-325 \\ Published Online April 2021 in IJEAST (http://www.ijeast.com)}

factors aside from the face vicinity, however the tool nonetheless pertains a couple of drawbacks because it can't encounter the top count number which can be a gift due to overlapping of faces or wrong reputation of faces having comparable facial functions.

-Find faces - regardless of whether or not the errand of perceiving people in photos, or video acknowledgment, or anything.

- Face positioning - pics arent frequently positioned on which an person stand straightforwardly before the main target , regularly the face grows to return to be, we're browsing the task of situating it as aleven though the image come to be taken legitimately.

-Defining outstanding facial capabilities - this improvement could also be referred to as an entire face acknowledgment step, it examinations the image and receives actually one altogether a sort computerized estimations of the face.

-Identification of an individual - we evaluation a got records and therefore the records efficiently handy to us, if the info are similar, we will display the choice of the character, if not, in like manner weve not regarded at this factor to us character. this may examine intimately all of the approach to fabricate a face acknowledgment framework and evaluation their execution and therefore the assist of diverse libraries, without a doubt because the rate of crafted with the help of using manner of every introduce diverse libraries of Computer vision.

\section{CONCLUSION}

In the beyond few years, facial popularity era has come a protracted way. Today can test identity data robotically with regard to secure transactions, tracking, security functions and houses get admission to regulate. Such structures typically paintings in controlled environments and algorithms of recognition also can additionally manage environmental constraints to get excessive accuracy of recognition. Yet facepopularity technology of subsequent technology could be normally utilized in clever settings where computer systems and machines are greater like supportive helpers.

\section{REFERENCES}

[1] Learning OpenCV -Computer Vision with the OpenCV Library O'Reilly Publication.

[2] Learning OpenCV: Computer Vision with OpenCV Library, Kindle

Edition.Gary Bradsk1 and AndrianKehlar

[3] M.A. Turk and A.P. Pentland, "Face Recognition Using Eigenfaces", IEEE Conf. on Computer Vision and Pattern Recognition, pp. 586-591, 1991.

[4] "KyungnamKim" Face Recognition using Principle Component Analysis"

[5] Codacus: https://youtu.be/1Jz24sVsLE4
[6]B.Sumanth Immanuvel,Dr.C.K.Gomathy,Article:A machine Learning Approach to mark Attendance using Haarcascade Classifier, International journal for research and Development in Technology,Volume-11,Issue-3,March 2019.(ISSN No:2349-3585)

[7] Dr.C K Gomathy, Article: An Effective Innovation Technology In Enhancing Teaching And Learning Of Knowledge Using Ict Methods, International Journal Of Contemporary Research In Computer Science And Technology (Ijcrcst) E-Issn: 2395-5325 Volume3, Issue 4,P.No-10-13, April '2017

[8] Dr.C K Gomathy, Article: A Semantic Quality of Web Service Information Retrieval Techniques Using Bin Rank, International Journal of Scientific Research in Computer Science Engineering and Information Technology ( \begin{tabular}{l|l|l} 
IJSRCSEIT ) Volume 3 & Issue 1 & ISSN : 2456-3307,
\end{tabular} P.No:1563-1578, February-2018

[9] Dr.C K Gomathy, Article: A Web Based Platform Comparison by an Exploratory Experiment Searching For Emergent Platform Properties, IAETSD Journal For Advanced Research In Applied Sciences, Volume 5, Issue 3, P.No-213220, ISSN NO: 2394-8442,Mar/2018

[10] Dr.C K Gomathy, Article: A Study on the Effect of Digital Literacy and information Management, IAETSD Journal For Advanced Research In Applied Sciences, Volume 7 Issue 3, P.No-51-57, ISSN NO: 2279-543X,Mar/2018

[11] Dr.C.K.Gomathy, A.V.Sripadh Kaustthub, K.Banuprakash, Article: An Effect of Big Data Analytics on Enhancing Automated Aviation, International Journal Of Contemporary Research In Computer Science And Technology (Ijcrcst) E-Issn: 2395-5325 Volume 4, Issue 3,P.No-1-7.March -2018

[12] Dr.C K Gomathy, Article: A Semantic Quality of Web Service Information Retrieval Techniques Using Bin Rank A Cloud Monitoring Framework Perform in Web Services, International Journal of Scientific Research in Computer Science Engineering and Information Technology IJSRCSEIT | Volume 3 | Issue 5 | ISSN : 2456-3307,May-2018

[13] Dr.C K Gomathy, Article: Supply chain-Impact of importance and Technology in Software Release Management, International Journal of Scientific Research in Computer Science Engineering and Information Technology ( IJSRCSEIT ) Volume 3 | Issue 6 | ISSN : 2456-3307, P.No:14, July-2018

[14] Dr.C K Gomathy, Article: A Scheme of ADHOC Communication using Mobile Device Networks, International Journal of Emerging technologies and Innovative Research ( JETIR ) Volume 5 | Issue 11 | ISSN : 2349-5162, P.No:320326, Nov-2018

[15] Dr.C K Gomathy, Article: A Study on the recent Advancements in Online Surveying, International Journal of Emerging technologies and Innovative Research ( JETIR ) Volume 5 | Issue 11 | ISSN : 2349-5162, P.No:327-331, Nov2018. 
[16] C.K. Gomathy, V. Geetha, Venkata Nagendra, Venkata Sai Ram, Article: The Secured Proficient Smart Electronic Voting System, International Journal of Engineering and Advanced Technology (IJEAT) ISSN: 2249 - 8958, Volume-9 Issue-4, April 2020

[17] V.Geetha, C.K.Gomathy, P.Manojkumar, N.S.L.S.V.Manohar, Article: The Sentimental Analysis for ECommerce Application, International Journal of Engineering and Advanced Technology (IJEAT) ISSN: 2249 - 8958, Volume-9 Issue-5, June 2020

[18]CKGomathy,V Geetha,P.S.lavakumar,K.V.Rahul,The Efficient Automatic Water Control Level Management Using Ultrasonic Sensor, International Journal of Computer Applications (0975 - 8887) Volume 176 - No. 39, July 2020

[19]VGeetha, C.K. Gomathy, Maddu Pavan Manikanta Kiran, Gandikota Rajesh, The Implementation of Fleet Monitoring System using Mobile based Software, International Journal of Engineering and Advanced Technology (IJEAT) ISSN: $2249-$ 8958, Volume-9 Issue-4, April 2020

[20]C K Gomathy, Student Location Tracking Inside College Infrastructure, International Research Journal of Engineering and Technology (IRJET) e-ISSN: 2395-0056 Volume: 07 Issue: 06 | June 2020. 